\title{
Navigating Children's Participation Rights in Education in Low-Income Countries
}

\author{
Catherine Vanner \\ Faculty of Education, University of Ottawa, Canada
}

\begin{abstract}
Proponents of a children's rights-based approach to education assert that children should be able to participate in the educational decisions that affect them. This paper examines this assertion from an international development perspective, highlighting the importance of student voice and also challenges to its facilitation. It begins by describing the benefits of children's participation in education based on the extensive literature from Western highincome country contexts. A series of case studies of children's participation in education in middle and low-income countries illustrate possibilities and challenges for the realization of children's participation rights in education in light of national policies and NGO initiatives.
\end{abstract}

\section{Introduction}

The potential benefits of involving children in the planning, implementation and monitoring of education programming are numerous, ranging from improving the quality of education to enhancing the self-esteem of participating children. Children's participation in education is a complicated process with many obstacles that must be navigated to successfully achieve a state in which children and adults become partners in the education process. While there is extensive literature regarding the theory of children's participation in education and its practical application in Western country contexts, there is a significant need for further exploration of children's participation in education in non-Western countries, particularly in low-income countries that face the challenges of limited human and financial resources, and cultural values and power structures that may oppose children's participation. As learning achievement remains very poor in many low-income countries, further study on the application of children's participation models in education in these countries is imperative to explore the potential to enhance quality of education, learning outcomes and children's well-being where most needed.

Article 12 of the CRC asserts that: "States Parties shall assure to the child who is capable of forming his or her own views the right to express those views freely in all matters affecting the child, the views of the child being given due weight in accordance with the age and maturity of the child"[1]. The recognition of children's agency indicates a significant shift in the role of and attitude toward children in many cultures, making Article 12 one of the most radical provisions of the CRC. Unfortunately, it is also one of the most widely violated and ignored in almost every area of children's lives [2]. Article 12 imposes an obligation on adults to ensure that children are enabled and encouraged to contribute their views, and that these views be taken seriously and inform the decisions that affect children [3]. It does not propose providing children with complete autonomy or unlimited control over their lives and the legal and social services from which they benefit. While the CRC considers a child as any person under the age of 18 , the only limitation within the right to participation is that the views of the child being given due weight according to their age and maturity. This qualification places the obligation on decisionmakers to not only consult and involve children but also to assess the capacity of the child in terms of age and maturity when considering their views.

\section{Facilitating Children's Participation in Education}

\subsection{The Rights-Based Approach}

As education has a clear and direct effect on children, Article 12 of the CRC therefore requires state parties to ensure that children have an opportunity to express their opinions on matters regarding their education, and that their expressed opinions are considered when decisions about their education are made. A rights-based approach to development is one in which all programmes, policies and technical assistance further the realization of human rights; therefore human rights principles and standards guide all phases of the programming [4]. In a children's rights-based approach, all phases of the programming should be guided by the CRC and other relevant children's 
rights doctrines. This approach prioritizes the dignity of the child as a human being and demands the space for participation both as an end in itself and as a means to facilitating other rights.

\subsection{Models of Children's Participation}

The first model identifying a framework for children and young people's participation was Hart's (1992) Children's Participation: From Tokenism to Citizenship. The ladder has eight different rungs, each signifying a different level of children's participation. The first three (manipulation, decoration and tokenism) are levels of nonparticipation, followed by the participation rungs: assigning and informing; consulting and informing; adult-initiated shared decision-making; young people-led and initiated action; and young peopleinitiated shared decision-making [5]. The ladder is not intended as an evaluative tool but as a schema to establish a clear and simple framework to launch a critical discussion and consideration of the subject [6].

In 2001, Shier modified Hart's ladder to establish his own framework, Pathways to Participation. Shier borrows only from Hart's five rungs of actual participation, describing these levels as: children are listened to; children are supported in expressing their views; children's views are taken into account; children are involved in decision making; and children share power and responsibiltiy for decision making. For each of these levels he then identifies three stages of an organization's commitment to facilitating participation: openings, opportunities and obligations. Shier and Hart's models have been criticized for being linear and for the implication that certain levels are superior to others, which could discourage organizations from engaging in lower levels. Hart responded to this criticism by insisting that some levels are superior to others and that, while not all organizations need to engage in the highest rungs of the ladder, children should have and be aware of their opportunity to do so [6].

There are many different activities that can constitute children's participation in education. It is most common at the school level but can also be facilitated at the national, state or district level. The possibilities are wide-ranging, and no set of activities is necessarily more significant than others. Participation activities must be selected based on the educational context and consider children's age, the length of their engagement, the objectives of the initiative and of the children's participation methodology, and the openness of adults involved to children's engagement. Some of the most prominent forms of children's participation in education include student councils, children as researchers or consultants, or student representation on evaluation, assessment or recruitment committees.

\section{The Benefits of Children's Participation in Education}

In a literature review that looked at seventy-five studies of pupil participation, mainly in the UK but also internationally, the authors commented that "we have not come across a single study where a school or college has gone back on student involvement and actively decided that it is not wanted" [7]. They observe that, while occasionally pupil participation fades due to the departure of an enthusiastic teacher or a decline in the effectiveness of a school council, most often pupil participation in decision-making begins a process that generates a chain of benefits. The combination of increased efficacy of education programming and increased student engagement can lead to increased test scores, improvement in student behaviour and enhanced overall ethos of the school [8]. Therefore, realizing children's participation rights in education enhances the effectiveness and efficiency of education programming, ultimately contributing to improved learning outcomes for children.

\subsection{School Effectiveness}

A pragmatic argument in favour of children's participation is that it leads to improved quality of service provision and more effective child-oriented policies and programming $[9,2]$. Involving children in school planning and policy implementation causes the education process to become more empowering, participatory, transparent, accountable and result in improved educational outcomes [10]. When children have more ownership in the education process, the school becomes more responsive to children's learning needs and children become more engaged in the education process. It has been demonstrated that children who feel valued, who recognize that there are mechanisms for dealing with injustices, and who are consulted over the development of school policies are far more likely to respect the school environment and want to be at school than children who are treated solely as recipients of education [3].

Education administrators are better able to understand the needs of students through dialogue with them. The contribution and consideration of students' viewpoints leads to more informed decision-making. "Giving children and young people a 'voice' should not be presented as doing them a favour. Their contribution should be appreciated as a highly valuable, special input into education decision-making. The primary benefit of the participation should be better decisions" [11].

A frequent aspect of improved school environment and effectiveness resulting from pupil participation in school decision-making is strengthened student-teacher relationships. The 
collaborative process and increased dialogue between the two groups enhances their understanding of the other group's situation, and begins to bridge the divide between teachers and students. While this is threatening to many teachers, it can improve students' perspectives of teachers [12] by helping students to empathize with teachers, understand the pressures they are facing and consider teachers as allies in their learning. Teacher-student dialogue also helps teachers better understand students' perspectives. Students in a Rudduck and McIntyre (2007) study argued that they knew better than their teachers what strategies help them learn, and that consultation was necessary to assist teachers in the creation of opportunities and approaches that students enjoy and believe support their learning.

The impact of student participation directly on learning outcomes is more difficult to determine. Logically, the demonstrated benefits of improved school effectiveness should lead to increased learning outcomes, as the school is better able to achieve its main objectives of teaching and learning. However, it is difficult to make direct connections between the impact of student participation on learning, achievement and performance. Cumulative evidence suggests a positive correlation [13, 14, 15], but it may emerge from the combination of other benefits, such as more informed school decisionmaking, improved teacher-student relations and improved school environment, for which the evidence of a direct causal link is much stronger than it is for increased learning outcomes [7]. It is likely that positive effects on student learning achievements at a school level will be observed over the long term as a consequence of sustained improvements in school effectiveness, as well as the other benefits identified below.

\subsection{School Environment}

Along with improved student-teacher relations, evidence demonstrates that student participation leads to a more peaceful school environment. "Children who feel valued, feel that there are systems for dealing with injustices, and who are consulted over the development of school policies are far more likely to respect the school environment" [16]. Student participation leads to higher rates of obedience to rules as students are more able to understand why the rules are in place. The sense of being trusted is validating for children, causing them to respond with increased trust in and respect for the system [17]. In some instances, children play a role in shaping the rules, in which case their accountability to them is greatly increased; it has been demonstrated that rules are better kept by both staff and students if they are democratically agreed to $[17,18]$.

\subsection{Individual Benefits to Students}

Beyond the benefits outlined for school environment and efficacy, there are extensive positive impacts that student participation in education can have on a more individual level. Students' involvement in decision-making enhances their individual engagement with the learning process, often leading to increased motivation and self-identification as learners. In some instances, benefits are more pronounced in under-performing students, leading to reversals in patterns of attendance and retention. For example, in the study of adolescents' democratic engagement in a special vocational school in England, some of the contributing students became regular attenders after long periods of absenteeism, finding for the first time meaning and enjoyment in education [19]. Engagement in decision-making processes provide contributing students with a degree of ownership towards the school, where they develop a sense of commitment and responsibility towards it [3]. The sense of responsibility leads to a more peaceful school environment, as outlined above, but can also lead to enhanced individual understanding and respect for education. Students who contribute to the school often change from passive recipients of education services to active contributers to the system. They become more invested in their own education, better understand the learning process and take increased responsibility for their learning [20, 21].

Students' participation in education decisionmaking through mechanisms such as school councils often leads to enhanced academic performance of participating children [7]. Although the link between student participation and improvement in learning outcomes is indirectly correlated at the school level, on an individual basis the evidence demonstrating a causal link is stronger. An important distinction is that benefits emerging from improved school environment and effectiveness positively impact all children in the school. By contrast, increased engagement with learning has been observed in relation to the participating children in particular. Typically, not all children in a school or classroom are involved in education decision-making, planning or policy implementation to the same degree. Rather, a small sample of students are selected to represent their peers. The individual benefits that lead to improved attendance, retention and learning achievements only extend to the sample of students contributing.

Individual benefits for participating children also include increased self-esteem, improved confidence, increased self expression and more developed leadership skills [2, 21]. The effect of being consulted and listened to on the individual child can extend beyond the classroom, often having a strong 
positive impact on participating children on a personal level. When children's views are seriously considered and reflected in the development of their school, the child's recognition that their opinions are respected enhances their confidence in these opinions and by extension in themselves.

Student participation also helps develop learning skills such as a prioritization, inquiry, social competency, communication and creativity [21, 22]. The impacts on individual students are often most pronounced in vulnerable children. Vulnerable youth can develop enhanced relience and capacity to resist maltreatment through participatory experiences [9]. It has also been noted that students with special needs or moderate learning disabilities experience dramatic increases in self-esteem subsequent to consultation in education decision-making [23]. The improvements in self-esteem, motivation, ownership and empowerment create a "benign circle" [13] where students' increased comfort and confidence resulting from these activities encourages them to get involved in other activities requiring motivation and self-confidence, which then further enhance these qualities in the student. These benefits have the potential to permanently shift the trajectory of a child's development. The challenge is that the benefits are primarily realized in participating children, which normally do not constitute the entire student body. While each context is different, the needs of the school should be examined to determine how different strategies for student involvement can reach as large a proportion of students as possible. Strategies for targeting more marginalized groups of children, who are least likely to independently volunteer to participate yet potentially stand the most to gain from the experience, are necessary to secure their involvement.

\subsection{Democracy and Citizenship}

A final argument favouring children's participation in education is that it is a powerful form of democracy and citizenship education: "Children's role as citizens and their understanding and awareness of democracy is determined by the extent to which their participation rights are respected" [24]. The practical application of democratic and inclusive models is a more effective approach to communicating the benefits and ideals of democracy and citizenship to students than only learning about them in the abstract. The practice of democratic processes can strengthen students' commitment to and understanding of democracy: "They need opportunities to participate in democratic decisionmaking processes within the school and community and learn to abide by subsequent decisions... Only by experiencing [the democratic process] will they acquire the capacity and willingness to listen to others and understand the processes and value of democracy" [25]. Democratic models and student engagement in school management can be seen as an "apprenticeship in democracy" [26] that lay the "groundwork for citizenship and democratic participation" [27]. The learning-by-doing process teaches students the challenges, benefits and pitfalls of democratic systems in a way that will stay with them and shape their future attitudes towards democracy.

Unlike the observed benefits of increased selfesteem and educational engagement that are perceived in participating students but are less evident in their peers, increased understanding of democracy and citizenship extends to the entire student body. While the benefits of improved interpersonal communication and political skills will be more pronounced in the student representatives that are directly contributing to the school's process for consultation, dialogue or integration of students into school management, when the student representatives are selected using a democratic process, all students are exposed to the implications of electing a peer representative.

Student participation in civic activities linked to the school develops their sense of responsibility and obligation to society, increasing the likelihood that they will continue to apply the citizenship skills they learned at school in their broader democratic communities [28] and providing them with the tools to engage effectively when they do so. The practical experience of democracy and citizenship within the school prepares children for their future engagement with their communities as adults, but it also engages students as contributing citizens in their school community immediately, teaching them that they do not have to wait until they are adults to have influence and their voices respected.

\subsection{Enabling Factors to Support Student Participation}

These benefits are encouraging, but it is important to remember that the nature of the participatory process will determine the strength of its results. A one-time consultation with a small group of students will have a very different impact than a long-term, established and systematized dialogue with student representatives of different ages and backgrounds. Selection and planning of the appropriate approach is a delicate undertaking with many factors to be considered. Student representation has the potential to be divisive by placing a small group of students in a privileged position. Teachers and education adminsitrators may also struggle with the introduction of more participation by students in school management, therefore ongoing communication about the process with these groups is critical as their support is crucial for the effectiveness and sustainability of student 
participation. The potential benefits are so significant that the case for increasing student participation in education decision-making is clear; however, the approach(es) for engaging students require serious consideration of the school and community context before advancing with the process of student participation. It must include ongoing adaptation of the process to reflect the needs of the school, teachers, administrators and, of course, the students.

\section{Examples of Children's Participation in Low-Income Countries}

While there is limited literature to date analyzing children's participation in education in low-income countries, there are some important case studies that will serve as the foundation for this literature to build upon. The following provides examples highlighting different forms of children's participation in education in Brazil, Tanzania, Zambia and Nepal.

\subsection{Participatory Mechanisms in Brazilian Schools}

While not a low-income country, Brazil provides a powerful case for the recognition of children's rights and student empowerment in a non-Western country context. There are a number of school mechanisms in which students can participate in Brazil: school assemblies, where the whole school community collectively takes decisions on key issues; school councils, in which students, teachers and community representatives weigh in on executive decisions; and grêmios, which are associations of pupils elected by their peers to organize cultural, sporting and political activities, and to act as a forum for discussions and a mouthpiece for the student body [8]. The participatory school culture pays tribute in part to the concept of Freirian dialogue, outlined by Freire in 1970 in his landmark Pedagogy of the Oppressed. Freirian dialogue involves the radical restructuring of student-teacher relations and a social process of knowledge construction and acquisition [29]. This idea of dialogue and joint knowledge construction that challenges traditional hierarchies informs the multiple student participation mechanisms in place in Brazilian schools.

McCowan (2010) observes that, while little evidence exists on the effects of pupil associations and pupil councils, students' accounts of their experiences with the grêmios indicate that those elected as representatives had very rich experiences. Students not elected, however, did not feel they benefited from the existence of the grêmios and "were skeptical about its political nature and efficacy in giving a voice to student views" [30]. In the Brazilian context, student participation is institutionalized in schools, however the primary approach used is only reaching a minority of students. The school assemblies' model presents a very inclusive approach, reaching all children in the school, and further investigation into the effectiveness at the school level and impact on students may demonstrate the usefulness of simultaneously applying multiple forms of student participation to engage different parts of the student population to varying degrees.

\subsection{Student Involvement in Parent-Teacher Associations in Zambia}

In Zambia, the Ministry of Education commits to facilitating the full participation of communities in educational provision [31]. The community referred to, however, refers to adults; the role of children in school governance is not raised and the PTA guidelines in the Education Act do not reflect children as stakeholders with decision-making rights in basic schools [32]. In a study of children's participation in 26 Zambian schools by Chiwela (2010), varying application of children's participation mechanisms was observed. There was a lack of understanding among education administrators as to what constituted children's participation, therefore what was applauded by some schools as child participation was actually involving them in the implementation of decisions made by adults. For example, at one school where adults stated there was full children's participation yet children were not represented on the PTA, it became evident that the participation element was taking part in the transportation of construction materials. Across the schools, students were represented on different school committees; in some instances pupils supported the claims that their opinions and suggestions were given consideration, while in others they did not. Chiwela advocates for a clearer definition of the roles of children to emphasize their place as critical stakeholders in education and clear policy direction to give schools a mandate and guidelines for active inclusion of children's participation.

\subsection{Secondary School Councils in Tanzania}

Tanzania provides a unique example of education policy in Sub-Saharan Africa that recognizes the importance of student participation in schools. This is entrenched in Education for Self Reliance (ESR) by Julius Nyerere, the former President of Tanzania and a former teacher. His publication sought to establish a set of education policies for producing schools and citizens more based on African socialism than European colonial education systems. A key aspect of ESR was democratic organization of secondary schools and student involvement in 
decision-making: "...only then can the participants practice - and learn to value - direct democracy... the pupils must be able to participate in decisions and learn by mistakes" [33]. The Government of Tanzania National Policy on School Councils describes the composition of a school council and its functions, including: educating students on government policy; being the advisory body to the head teacher on student matters; looking after school discipline; discussing and giving suggestions on school regulations; making sure school regulations are honoured and followed; and monitoring income and expenditures related to the school's production activities [34]. The extent to which these councils really exist in schools and the way that they function is questionable, with indications that the majority of schools remained authoritarian and reinforce passive subordination among students in spite of the policies promoting their empowerment [35].

Even if implementation of democratic principles in secondary schools did not live up to the aspirational guidance provided in the ESR policy, Harber indicates that the Tanzanian approach is still significantly distinct from the bureaucraticauthoritarian nature of school organization in much of Africa [36, 37]. Harber investigated two 'successful' student councils in Tanzania and found that the improvements to school effectiveness realized in UK schools, including improved communication and school management, were similarly realized in Tanzanian schools even with limited financial resources [38]. Harber's study demonstrates that limited financial resources are not necessarily a barrier to effective student participation and, in fact, by improving the effectiveness of school management, student participation can potentially lead to increased efficiency of spending and less pressure on constrained school budgets. Perhaps even more significant is that Nyerere's groundbreaking anti-colonial education policy based in African social values, Education for Self Reliance, included mandatory secondary school student councils, making a compelling argument against the concept of student participation as a Western framework inappropriate in alternative cultural contexts.

\subsection{Children's Clubs in Nepal}

Children's clubs have become a widespread phenomenon in Nepal, beginning in the early 1990s following the establishment of the CRC. The clubs have been almost exclusively facilitated by international development NGOs [39]. In the past decade, the number of children's clubs has continued to grow, and today there are estimated to be thousands of children's clubs in Nepal supported by Save the Children alone [40]. The clubs, for the most part, have open membership and are governed by a small executive of elected children. The age range is eight to eighteen, however the executive is almost exclusively made up of children over thirteen. The clubs engage in a range of activities including recreational activities, community awareness, school and community cleaning, and informal education. Participation and retention has been very high [39].

The children's clubs are not school-based and are therefore inclusive of children both in and out of school. While not all clubs deal directly with school processes and decision-making, some do. Bhattari (2010) looked at two case studies of children's clubs that had been working actively to eradicate violence against children, including corporal punishment in their local schools. The Everest Children's Club in Bhaktapur provided training to children's groups in schools and met with teachers to discuss the importance of not hitting children. Teachers resisted initially, but slowly accepted the idea when approached by the children as a group. In the Naram Bal Bikas Children's Club in Nawalparasi, the club discusses every instance of violence against children in the community (including corporal punishment in schools) at their monthly meetings, followed by speaking to the instigators of the violence and facilitating counseling for affected children. The perpetrator is provided with an initial 'warning' but if the behaviour is repeated the club publicly shames the individual in their newsletter. The clubs have had a positive effect on the school environment: teachers say that children have become more responsible and the need for disciplinary action does not arise. Children report that teachers have more respect for students and do not give them harsh punishment because they do not want to "lose face" [41]. The most commonly reported outcome from the clubs is increased confidence among children [42], which they attribute directly to the clubs. The 17-year old vice chair of the Everest Children's Club stated: “Oh, impact? I wouldn't be able to speak with you if I was not in the club!"' [43].

While the children's clubs demonstrate a very positive trend in favour of children's participation in Nepal, the NGO-driven nature of the clubs leads to questions about the sustainability of the clubs if they cease to receive financial support and technical facilitation from the organizations [40]. There have also been concerns around the extent of inclusion in the clubs. While they incorporate in and out of school children and maintain a reasonably strong gender balance, with $4 \%$ fewer girls in the general membership, inequalities persist in the general membership and are more pronounced in the executives: participation is significantly lower among children from lower castes and local minority groups, and none of 22 case study clubs had any special needs children [39]. Most children's clubs have adult facilitators or advisors, yet few of these individuals have received training in group 
facilitation or children's rights and, consequently, their behaviours vary greatly: "Some encourage the children to decide things themselves and to develop their own strategies for club membership. Others are more directive, believing that they know more than children and must lead them rather than advise" [43]. Therefore, significant progress and a solid foundation for children's participation in the community and schools is established in Nepal, yet it continues to be dependent on initiation and support from NGOs, and targeted efforts need to be scaled up to ensure that all children have the opportunity to participate, and that their full participation in decision-making is at the heart of the process.

\section{Challenges Realizing Children's Participation in Low-Income Countries}

Despite the numerous benefits of children's participation in education outlined above, there remains limited application of children's participation models in education in low-income countries. This is due in part to the many challenges that accompany children's participation.

\subsection{Lack of Established Framework}

There is no established framework that outlines exactly what children's participation entails. There is a general consensus as to the key principles that must inform the overall approach to children's participation $[44,45]$ but these are not specific to the education sector and do not explicitly outline actions to ensure the principles are met. Children's participation can entail any number of activities, including one-off consultations, longer-term consultation processes such as children's forums or advisory groups, ongoing involvement in the governance of institutions, children-led organizations, and children as researchers [46]. Activities specific to education include children as peer mentors, school councils, helping to develop school policy including behaviour codes and discipline, advising on playground and school design and location, contributing to the curriculum, providing feedback on teaching methods, as mediators to resolve conflicts and participating in school governing committees [10]. While the breadth of activities allows for flexibility in meeting the needs of a specific school or community, it also makes implementation more difficult as there are not clear steps or guidelines to follow.

\subsection{Limited Capacity and Resources}

Whatever form a children's participation model takes, it is inevitably a delicate and complicated undertaking, making strong educational leadership from a head teacher or principal and teachers themselves critical. Education in many low-income country contexts is characterized by poor quality of instruction and weak school management, posing a significant obstacle in the effective implementation of children's participation approaches. While there is limited evidence related to children's participation in education in low-income countries, certain assumptions can be drawn from the literature on student-centered pedagogy, an approach which entails a high level of children's participation in classroom learning. Significant challenges around stronger recognition of student voice have arisen regarding the application of student-centered pedagogy in Sub-Saharan Africa: it is argued that the approach is unrealistic in Sub-Saharan African countries due to material inequalities in schools and the more advanced skill sets teachers require to apply a student-centered pedagogical model [47, 48]. Many of the challenges related to student-centered learning would be applicable as well in advancing children's participation in education, as investments in children's participation are similarly complex and time-consuming, requiring significant human resources.

\subsection{Cultural Attitudes}

Another significant challenge that has been encountered is cultural attitudes that are considered incongruous to children's participation. In accounts related to both student-centered pedagogy and children's participation in education more broadly, culture was considered a significant barrier as the prevailing culture encouraged children to be quiet, obedient and not to express their opinions. In Zambia, the belief that children should remain silent in the presence of adults was observed to be a challenge in facilitating children's participation, as it caused children to be hesitant to speak and adults to be uncomfortable with the child who expresses an opinion [49]. In Ghana, children who express their views are considered to be disrespectful and are reprimanded for speaking out [33]. A cultural perception that children should be seen and not heard is clearly contradictory to a children's participation framework which encourages children's active and vocal contribution to decision-making. Of note is that the same cultural perception of the role of the child as one of quiet obedience described above in relation to Ghana and Zambia is also present in Western societies [50], although perhaps to a lesser degree. Therefore cultural sensitivity as to the role of children will likely be a crucial consideration in many different cultural contexts. 


\subsection{Power Structures}

The most significant obstacle to children's participation is often the reluctance of adults to relinquish complete control over decision-making, which is necessary to varying degrees depending on the level of children's participation. Most commonly, obstacles to youth participation originate in adults' inability to consider the possibility of youth participation as a process dependence on guidance, dialogue and gradual shifting power arrangements [51]. Convincing teachers and education administrators to create a space for dialogue with children is essential to securing sustainable children's participation. Given the hierarchical structure of the school and classroom, which places power and control firmly in the hands of teachers and administrators, adults' unwillingness to share power is particularly prominent in school settings. Teachers often view children's empowerment and participation as a "dangerous challenge to traditional teaching authority" and this is even proposed to be the reason that education has not promoted children's participation in decision-making as actively as some other sectors [9]. Based on this review, the main challenges to be considered when engaging children's participation in education in developing country contexts are cultural perceptions of children's role in education, limited capacity of teachers and education administrators to implement a children's participation model, limited financial resources while numerous other costly education improvement initiatives are simultaneously underway, and the reluctance of teachers and education administrators to share power with children.

\section{Conclusion}

According to the CRC, children's participation should already be an inherent component of all initiatives in which children are affected. The case for further exploration of children's participation in education is clear: in the research conducted to date, extensive benefits have been observed in numerous areas and on multiple levels. While challenging, when the model of children's participation extends beyond tokenism, no negative patterns have emerged. In contrast, the following positive outcomes have been realized in numerous studies and evaluations: improved responsiveness of school policies to students' learning needs; improved pupilteacher relationships and communication; more peaceful school environment; increased student obedience to school rules; enhanced self-esteem, self-confidence and communication skills of participating students; and improved understanding of the values of democracy and citizenship. These positive outcomes in turn lead to improved learning outcomes and achievement in terms of student retention and academic performance. These benefits have been primarily observed in Western highincome countries.

While a small number of case studies across a broad geographical range of low-income countries indicate the benefits may be similar in low-income country contexts, it is unclear the extent to which a more challenging policy environment characterized by low financial and human resources and opposing cultural attitudes will compromise benefits in lowincome countries. Further research needs to precede policy recommendations related to children's participation in education in low-income countries. Exploration of benefits realized from initiatives arising as a result of a variety NGO initiatives and national education policies must be comprehensively examined in a given country context to assess the extent of potential educational benefits and test a variety of strategies to overcome the challenges noted above.

Children are rarely given the chance to participate in the decisions that shape their school experience, even though these decisions may influence the rest of their lives and almost all states have internationally committed to providing children the opportunity to express their opinions and contribute to decisionmaking in areas that affect them, including education. Given the low quality of education and learning achievement in terms of student retention and academic performance in many low-income countries, and the potential benefits that student participation could have in these areas, the imperative to engage students in educational decision-making is even stronger in these contexts, yet it is where the least amount of research exists. By focusing more efforts on student voice in education internationally and building the evidence base of effective strategies and educational benefits in a variety of country contexts, children's participation will become more prominent and easier for different groups to advocate for and monitor in schools. The elaboration of student participation strategies that have to date only been explored on the surface will lead to the establishment and development of models that can be adapted and applied in various country contexts. These strategies may lead to increased school effectiveness in teaching and learning of core subjects and democracy and citizenship and skills such as cooperation and communication where the need for these educational benefits is most urgent. If these outcomes are at all possible, and the handful of examples described here indicates they may be, then further exploration of children's participation in education should be a critical priority for all stakeholders supporting education in low-income countries. 


\section{References}

[1] UN General Assembly, Convention on the Rights of the Child, United Nations, New York, 1989.

[2] Shier, H., "Pathways to Participation: Openings, Opportunities and Obligations", Children and Society, 15, 2001, pp.107-117.

[3] Lansdown, G., Promoting Children's Participation in Democratic Decision-making. UNICEF Innocenti Research Centre, Florence, 2011.

[4] UN Development Group, UN Statement of Common Understanding on Human Rights-Based Approaches to Development Cooperation and Programming, United Nations, 2003. Retrieved February 13, 2012, from HRBA Portal: www.hrbaportal.org.

[5] Hart, R., "Children's Participation: From Tokenism to Citizenship", Innocenti Essays, 4. UNICEF Innocenti Research Centre, Florence, 1992.

[6] Hart, R., "Stepping Back from 'The Ladder': Reflections on a Model of Participatory Work with Children", Eds. A. R. Nikel, J.B.Bruun Jensen, Participation and Learning: Perspectives on Education and the Environment, Health and Sustainability, Springer, Dordrecht, 2008, pp.19-31.

[7] Davies, L., Williams, C., Yamashita, H., and ManHing, A.K.D. Inspiring Schools: Impacts and Outcomes. Taking Up the Challenge of Pupil Participation, Carnegie, London, 2006.

[8] McCowan, T., “'Prefigurative' approaches to participatory schooling: experiences in Brazil", Ed. S. Cox, C. Dyer, A. Robinson-Pant and M. Schweisfurth, Children as Decision-makers in Education: Sharing Experiences Across Cultures, Continuum, London, 2010, pp. 15-25.

[9] Maclure, R., "The Pedagogy of Youth Participation: Insights from a Case Study in Senegal", Ed. S. Bennett and M. Pate, 20th Anniversary of the Convention on the Rights of the Child, University of Ottawa, Ottawa, 2009, pp. 116-124.

[10] UNICEF/UNESCO, A Human Rights-Based Approach to Education for All, UNICEF, New York, 2007.

[11] Yamashita, H., Davies, L. and Williams, C., "Assessing the Benefits of Students' Participation", Eds. S. Cox, C. Dyer, A. Robinson-Pant, and M.

Schweisfurth, Children as Decision-makers in Education: Sharing Experience Across Cultures, Continuum International Publishing Group, London, 2010, pp. 99-106.

[12] Rudduck, J. and McIntyre, D., Improving Learning Through Consulting Students, Routledge, New York, 2007.

[13] Hannam, D., A Pilot Study to Evaluate the Impact of the Student Participation Aspects of the Citizenship Order on Standards of Education in Secondary Schools, Department for Education and Employment, London, 2001.
[14] Trafford, B., School Councils, School Democracy, School Improvement, Secondary Heads Association, Leicester, 2003.

[15] Davies, L., School Councils and Pupil Exclusions, School Councils UK, London, 1999.

[16] Lansdown, G., Promoting Children's Participation in Democratic Decision-making. UNICEF Innocenti Research Centre, Florence, 2011, pp. 5.

[17] Fielding, M., "Students as Radical Agents of Change", Journal of Educational Change, 2(2), 2001, pp. 123-141.

[18] Harber, C., Developing Democratic Education, Education Now, Ticknail, 1995.

[19] Swain, J., "A Vocational Special College: Preparing Students for a Preparatory Democracy?" Disability, Handicap and Society, 8(3), 1993.

[20] Lodge, C., "From Hearing Voices to Engaging in Dialogue: Problematising Student Participation in School Improvement", Journal of Educational Change

[21] Flutter, J. and Rudduck, J., Consulting Pupils: What's In It For Schools? Routledge Falmer, London, 2004.

[22] Shier, H., "Letting Children Have Their Say", Play Matters, 1999.

[23] Gold, J. and Gold, T., Learning By Doing, School Councils UK, London, 1998.

[24] Smith, A.B., "Children and Young People $<$ s Participation Rights in Education", International Journal of Children's Rights, 17, 2007, pp. 149.

[25] Lansdown, G., Promoting Children's Participation in Democratic Decision-making. UNICEF Innocenti Research Centre, Florence, 2011, pp. 6.

[26] Yamashita, H., Davies, L. and Williams, C., “Assessing the Benefits of Students' Participation”, Eds. S. Cox, C. Dyer, A. Robinson-Pant, and M.

Schweisfurth, Children as Decision-makers in Education: Sharing Experience Across Cultures, Continuum International Publishing Group, London, 2010, pp. 100.

[27] Shier, H., "Pathways to Participation: Openings, Opportunities and Obligations", Children and Society, 15, 2001, pp. 113

[28] Mannion, G., "Children's Participation in School Grounds Developments: Creating a Place for Education that Promotes Children's Social Inclusion", International Journal of Inclusive Education, 7(2), 2003.

[29] Freire, P., Pedagogy of the Oppressed, Continuum International Publishing Group, New York, 1970.

[30] McCowan, T., "Prefigurative Approaches to Participatory Schooling: Experiences in Brazil," Eds. S. Cox, C. Dyer, A. Robinson-Pant, and M. 
Schweisfurth, Children as Decision-makers in Education: Sharing Experience Across Cultures, Continuum International Publishing Group, London, 2010, pp. 19.

[31] Government of Zambia, Education Our Future: National Policy on Education, Ministry of Education, ZEPH, Lusaka, 1996.

[32] Chilewa, G. M., "Participatory School Governance: Children in Decision-making in the Zambian Context", Eds. S. Cox, C. Dyer, A. Robinson-Pant, and M. Schweisfurth, Children as Decision-makers in Education: Sharing Experience Across Cultures, Continuum International Publishing Group, London, 2010, pp. 59-69.

[33] Nyere, J., Education for Self Reliance, Government Printer, Dar es Salaam, 1967, pp. 38-39.

[34] Government of Tanzania, National Policy on School Councils, Ministry of Education, Government Printer, Dar es Salaam, 1979.

[35] Mbilinyi, M., Education in Tanzania with a Gender Perspective, SIDA, Dar es Salaam, 1991.

[36] Harber, C., "International Contexts for Political Education”, Educational Review, 43(3), 1991, pp. 245-256.

[37] Harber, C., Democratic Learning and Learning Democracy, Education Now, Ticknall, 1992.

[38] Harber, C., "Democratic Management and School Effectiveness in Africa: Learning from Tanznia", Compare, 23(3), 1993.

[39] Rajbhandary, J., Hart, R., and Khatiwada, C., The Children's Clubs of Nepal: A Democratic Experiment, Save the Children, Norway, 1999.

[40] Bhattari, T., "Children's Clubs and Corporal Punishment: Reflections from Nepal”, Eds. S. Cox, C. Dyer, A. Robinson-Pant, and M.

Schweisfurth, Children as Decision-makers in Education: Sharing Experience Across Cultures, Continuum International Publishing Group, London, 2010, pp. 49-57.

[41] Bhattari, T., "Children's Clubs and Corporal Punishment: Reflections from Nepal”, Eds. S. Cox, C. Dyer, A. Robinson-Pant, and M.

Schweisfurth, Children as Decision-makers in Education: Sharing Experience Across Cultures, Continuum International Publishing Group, London, 2010, pp. 54.

[42] Bhattari, T., "Children's Clubs and Corporal Punishment: Reflections from Nepal”, Eds. S. Cox, C. Dyer, A. Robinson-Pant, and M.

Schweisfurth, Children as Decision-makers in Education: Sharing Experience Across Cultures, Continuum International Publishing Group, London, 2010, pp. 53.

[43] Rajbhandary, J., Hart, R., and Khatiwada, C., The Children's Clubs of Nepal: A Democratic Experiment, Save the Children, Norway, 1999, pp. 35.

[44] Cox, S., C. Dyer, A. Robinson-Pant, and M. Schweisfurth, Children as Decision-makers in Education:
Sharing Experience Across Cultures, Continuum International Publishing Group, London, 2011.

[45] Hill, M., J. Davis, A. Prout and K. Tisdale, "Moving the Participation Agenda Forward", Children and Society, 18, 2004, pp. 77-96.

[46] Cairns, L., "Investing in Children: Learning How to Promote the Rights of All Children", Children and Society, 15, 2001, pp. 347-360.

[47] Sinclair, R., "Participation in Practice: Making it Meaningful, Effective and Sustainable", Children and Society, 15, 2004, pp. 107-117.

[48] Vavrus, F., "The cultural politics of constuctivis pedagogies: Teacher education reform in the United Republic of Tanzania", International Journal of Educational Development, 29, 2009, pp. 303-331.

[49] O'Sullivan, M., "The reconceptualisation of learnercentered approaches: a Namibian case study", International Journal of Educational Development, 24, 2004, pp. 285-302.

[50] Twum Danso, A., "Reciprocity, Respect and Responsibility: The Three Rs Underlying Parent-Child Relationships in Ghana and the Implications for Children's Rights", International Journal of Children's Rights, 17, 2009, pp. 415-432.

[51] Thornberg, R., "Rules in Everyday School Life: Teacher Strategies Undermine Pupil Participation," International Journal of Children's Rights, 17, 2009, pp. 393-413. 